\title{
“DisCUlPE, SEÑOR JUEZ... ¿ME PERMITE DECIR UNAS PALABRAS?” IDENTIDADES, PERFORMANCES JURÍDICAS Y DRAMA SOCIAL EN LOS testimonios de sobrevivientes en la Mega Causa La Perla, Córdoba (ARGENTINA)
}

\section{"Excuse me, your Lordship... May I say some words?" Identities, judiciary performances and social drama in the testimonies of survivors at the Mega Trial La Perla, Córdoba (Argentina)}

\author{
Mariana Tello* \\ *IDACOR-Universidad Nacional de Córdoba. Espacio para la Memoria "La Perla" (Argentina) \\ marianitaweiss@yahoo.es
}

\section{Palabras clave Memoria Identidad Centros clandestinos de detención Víctimas}

\section{Keywords}

Memory Identity Clandestine detention centers Victims

\begin{abstract}
Resumen
En Argentina, lo judicial se configura como la principal vía a la hora de enfrentar las atrocidades cometidas durante la última dictadura (1976-1983), generando identidades como las de victimarios o víctimas. Si bien lo que define a estas figuras jurídicas es haber cometido o haber sido blanco de un delito; una aproximación antropológica a este caso revela la maleabilidad de estas representaciones y una constante disputa en torno a las mismas. El presente artículo se enfoca en un tipo particular de víctimas, las cuales son también los principales testigos de los crímenes cometidos durante la dictadura: los sobrevivientes de centros clandestinos de detención y exterminio. Más precisamente, busca analizar las memorias e identidades relacionadas con las experiencias concentracionarias a partir de una aproximación etnográfica a los testimonios judiciales vertidos en la Mega Causa "La Perla" (Córdoba, Argentina). El texto aborda cómo, en lo que se refiere a este grupo, las categorías de "testigos" o "víctimas" fueron construidas en diferentes escenas judiciales, para luego centrarse en las audiencias y específicamente en los pasajes con los que los sobrevivientes introducen sus testimonios. Estas introducciones resultan particularmente reveladoras en tanto contextos privilegiados para la disputa de las representaciones sobre los ' 70 , las identidades de sus protagonistas y, en términos más amplios, los procesos de gestión de esas identidades a lo largo de tres décadas.
\end{abstract}

\section{Abstract}

In Argentina, the judiciary has become the principal way to deal with the atrocities committed during the last dictatorship (1976-1983), framing identities either as perpetrators or victims. Although legally those identities are defined by the fact of having committed or having been the target of a crime; an anthropological approach to this case reveals the malleability of those representations and the continuous struggles around it. This article focuses in a particular kind of victims, who are also the main witnesses of the crimes committed during the dictatorship: the survivors of the clandestine detention and extermination centers. More precisely, it analyzes the memories and identities linked to the experiences of those who survived the clandestine detention centers, based on an ethnographical approach to the judiciary testimonies presented in the mega trial "La Perla" (Córdoba, Argentina). The article studies how categories such as "witnesses" or "victims" are constructed and performed through different judicial scenes. It then focuses on the court hearings, more precisely in the statements that survivors use to introduce themselves. These introductions are particularly revealing, constituting privileged contexts for the struggles on the representations of the 70s', the identities of their protagonists and the management of those identities over the last three decades.

Tello, M. (2017). “Disculpe, señor juez... ¿Me permite decir unas palabras?” Identidades, performances jurídicas y drama social en los testimonios de sobrevivientes en la Mega Causa La Perla, Córdoba (Argentina). Papeles del CEIC. International Journal on Collective Identity Research, vol. 2017/1, papel 167, CEIC (Centro de Estudios sobre la Identidad Colectiva), UPV/EHU Press, http://dx.doi.org/10.1387/pceic.17021 


\section{INTRODUCCIÓN}

El presente artículo se enmarca en un proceso de investigación más general que analiza las memorias e identidades en torno a las experiencias concentracionarias durante la última dictadura en Argentina (1976-1983), y más precisamente en el Centro Clandestino de Detención (CCD) conocido como La Perla'. A lo largo del mismo, analizaré cómo las memorias sobre el drama social (Turner, 1979, 1988) de los años 70 en Argentina se re-crean y performan en la escena judicial actual, disputando sentidos sobre el pasado reciente y sobre la identidad de sus protagonistas. Hacia finales de 2012 dio comienzo en Córdoba un juicio oral de gran magnitud por los delitos de Lesa Humanidad cometidos en toda la provincia: la Mega Causa "La Perla". De entre las causas judiciales acumuladas en la misma, me interesa analizar la llamada "Causa Acosta"2, por la cual se juzgó a 21 represores por los delitos de privación ilegítima de la libertad y aplicación de tormentos agravada cometidos contra 139 sobrevivientes.

Partiendo del trabajo de campo realizado entre los años 2012 y 2015 en las audiencias, y fuera de ellas, abordaré desde una perspectiva etnográfica ${ }^{3}$ el giro que habilitó en ese contexto el desplazamiento de las identidades de los sobrevivientes: de testigos a "víctimas-testigos". Así, analizaré las audiencias judiciales donde éstos comparecieron, para luego enfocarme en una parte novedosa de los testimonios vertidos en esta nueva etapa: las "introducciones" que anteceden al testimonio de algunos de ellos. Estos pasajes, que desbordan el ritual judicial en forma y contenido, se centran en la experiencia vivida en primera persona, etapas biográficas que quedan por fuera de los hechos que son objeto del juicio y que buscan otorgar un plus de comprensión a las

\footnotetext{
${ }^{1}$ El lugar - situado en las sierras de Córdoba, Argentina- funcionó como Centro Clandestino de Detención, Tortura y Exterminio entre marzo de 1976 y diciembre de 1978, siendo confinados allí alrededor de 2.500 prisioneros políticos, de entre los cuales unos 2.300 continúan desaparecidos. De 1979 a 2007 - momento en que fue sacado de la órbita del Ejército y entregado a la Comisión de la Memoria de Córdoba-, el lugar funcionó como cuartel militar, inaugurándose como Espacio para la Memoria en marzo de 2009.

${ }^{2}$ Se trata del expediente 16.618 caratulado como "Acosta, Jorge Exequiel y Otros. Privación llegítima de la Libertad y otros".

${ }^{3}$ Esta perspectiva construye conocimiento basándose en los modos de clasificación de los propios sujetos sobre su vida social, o lo que Bronislaw Malinowski (1973) llamó "el punto de vista nativo". La etnografía implica también un tipo particular de escritura que permita discriminar los términos "nativos", por lo cual en este trabajo los mismos serán entrecomillados, distinguiéndose así de las categorías analíticas o de mis reflexiones como autora.
} 

los mecanismos de gestión de esa "identidad herida" (Pollak y Heinich, 2006).

Lo analizado en este artículo emana de un trabajo de campo prolongado ${ }^{5}$ durante el cual, más allá de analizar sus testimonios previos en documentos, observé y realicé un registro etnográfico de las audiencias, acompañando las declaraciones judiciales de muchos sobrevivientes ${ }^{6}$.

\footnotetext{
${ }^{4}$ Michael Pollak (2006) adjudica el término "heridas" a las identidades atravesadas por situaciones límite, y el hiato moral que las mismas introducen en la coherencia entre el sentido del mundo y el sentido de sí.

${ }^{5}$ Como responsable del trabajo con los sobrevivientes en el área de investigación del Espacio para la memoria "La Perla" (emplazado en el ex CCD) desde 2008, he llevado adelante un trabajo tanto analítico como de intervención. Como institución, basándonos en diferentes fuentes hemos registrado un total de 187 casos de sobrevivientes (sobre un universo total de aproximadamente 2500 detenidos). Del total de sobrevivientes, hemos mantenido entrevistas con 98 , principalmente durante y con posterioridad a sus visitas a lo que fue su lugar de detención. Estando yo a cargo de esta tarea he acompañado -a excepción de unos pocos casos- prácticamente a todos, registrando estas instancias y las conversaciones mantenidas con posterioridad en una base de datos (destinada a consignar datos históricos) y mediante la escritura de un diario de campo. De esas 98 personas, he entrevistado en profundidad a 21. Con un estilo del trabajo de campo similar al de las etnografías clásicas me involucré en cada contexto donde se me requiriera, sobre todo en el acompañamiento en instancias judiciales. Así, los he acompañado a declarar en instancias de instrucción y, durante el desarrollo de la Megacausa, asistí a todas las audiencias donde declararan. Actualmente, comienzo a desarrollar otro proyecto (CONICET-IDACOR) que implicará la realización de historias de vida.

${ }^{6}$ La etnografía compele también a analizar de modo reflexivo mi posición en el campo y mi grado de implicación en este trabajo. Tratándose de experiencias que apuntaron a eliminar la confianza en otros y de trayectorias marcadas por estigmatizaciones, mi condición de "víctima de la represión" o "hija de desaparecidos", y de militante de un organismo de DDHH el cual ya había construido una relación con algunos de ellos, contribuyó a generar la confianza necesaria para emprender la investigación. Pero más allá de esta "cercanía social", lo que contribuyó a consolidar la confianza y los marcos óptimos para el habla fue la elaboración de contratos éticos explícitos y el control de ellos mismos sobre la información publicada mediante procesos de autorización que en la Institución construimos como normas éticas. A lo largo de todo este proceso, la reflexividad y la permanente discusión de las conclusiones de investigación en espacios colectivos (tanto en el equipo de trabajo del Espacio de Memoria como en instancias académicas) fue imprescindible para lograr equilibrar la cercanía empática y la distancia analítica que el problema demanda (ver Tello, 2013).
} 


\section{LOS '70 COMO DRAMA SOCIAL Y LA DISPUTA SOBRE LA IDENTIDAD DE SUS PROTAGONISTAS}

En Argentina, los '70 constituyen, más que un tiempo estrictamente cronológico, un tiempo mítico que condensa memorias en torno a la violencia política. Por un lado, los '70 evocan un tiempo convulso marcado por luchas insurreccionales y movimientos armados en pugna por diferentes modelos de país; por otro lado, y centralmente, remiten a una dictadura militar que dejó como saldo asesinados, desaparecidos, presos políticos, exiliados, niños apropiados, y un país devastado social y económicamente.

Tomando estos hechos atravesados por la violencia, "en forma positiva" al decir de Elias (2001), es que busco interrogarme, primero, sobre cómo la violencia política y la represión generaron identidades $y$, después, sobre cómo las mismas emergen de la trama de un drama social (Turner, 1979) que fue recordado, reelaborado y recreado una y otra vez en diferentes escenas rituales a lo largo de cuarenta años ${ }^{7}$.

Parto de la premisa según la cual, lejos de tratarse de identidades estáticas, existieron y existen disputas permanentes en torno a la nominación de los grupos y sujetos que protagonizaron aquellos conflictos. Que ciertos actores del drama social que representa la dictadura en Argentina sean clasificados como víctimas, victimarios y/o testigos a día de hoy parece un hecho evidente. Una mínima retrospectiva, sin embargo, revela que cada uno de esos términos no siempre refirió a los mismos grupos, teniendo una génesis y un devenir particular atravesado centralmente por la atribución de responsabilidades en los hechos de violencia que los mismos protagonizaron (Burgi-Gulob, 1998).

Los militantes políticos victimizados fueron catalogados por el Estado dictatorial como "enemigos internos", "subversivos" y "extremistas" susceptibles de ser asesinados, secuestrados, desaparecidos, privados de

\footnotetext{
${ }^{7}$ Aunque el planteo excede los límites de este artículo, me interesa tomar tanto de Elias (2001) como de Turner $(1979,1974)$ aspectos que los autores trabajan: en primer lugar, el acento en los procesos sociales y en el largo plazo; segundo, la relación entre individuos y sociedad-estructura en ambos casos, pero centralmente la noción eliasiana de "doble vínculo" (Elias, 2001); finalmente, el valor que ambos adjudican al conflicto. Al tratarse de episodios de violencia, dentro de los cuales los individuos encuentran dificultades para una nueva agregación a los estatus sociales predefinidos al tiempo que la misma estructura social tarda en reconfigurarse, estos conceptos, y sobre todo el de liminalidad - el cual alude a esos estados intermedios, de transición - resultan fértiles en el análisis (Turner, 1979, 1990).
} 
todos sus derechos. Posteriormente, y a partir de una pugna social y el reclamo de juicio y castigo hacia los miembros de las Fuerzas Armadas y de Seguridad, y de la consagración de lo judicial como modo de saldar las cuentas con el pasado, los que habían sido perseguidos pasaron a ser tipificados como víctimas. Los militares que usurparon el mando del Estado, por su parte, partieron de considerarse "salvadores de la patria" para devenir, tras las denuncias y sucesivos juicios, criminales contra la humanidad (Calveiro, 2001). Esta atribución y/o asunción de identidades se vio mediada en todos los casos por el poder del Estado y su capacidad de generar categorías a partir de separar culpables de inocentes (Bourdieu, 1999), y de poner esas categorías en escena a través de rituales de institución específicos.

Más allá de la estricta dimensión legal, donde la categoría de víctima se estructura en torno a quien fue blanco de un delito, y de su dimensión sociopolítica, que la torna un continente semántico que permite viabilizar reclamos y movimientos de corte identitario (Sarti, 2011), la categoría víctima debe ser referenciada también en relación a cambios de escala universal en la economía moral del sufrimiento, al decir de Fassin (1999), y ante todo a las políticas de Estado que, en cada contexto local y a través de dispositivos específicos, administran una sensibilidad hacia las "grandes catástrofes" y a los modos de lidiar con las mismas.

Estos procesos generaron también identidades diferenciadas al interior de los grupos victimizados. Si bien se trata de categorías disputadas y maleables, con los años las victimas por excelencia pasarían a ser aquellos que -al momento de la reapertura democrática - continuaban desaparecidos ${ }^{9}$, y tras ellos los asesinados, categoría que agrupa a aquellos

\footnotetext{
${ }^{8}$ Un rápido repaso comparativo por procesos de lo que en las políticas globalizadas referidas al tema se llama "justicia transicional" arroja luz al respecto: las comisiones de verdad y reconciliación en las cuales el testimonio busca sensibilizar más que acusar, sumadas a las políticas de reparación económica, construyen un tipo de víctima donde la ponderación del sufrimiento (como corolario del daño) es central. El caso argentino entre otros, tales como Camboya, Ruanda o los Balcanes-constituye en este sentido un caso disruptivo $y$, por lo tanto, oportuno para pensar en qué matices introduce la posibilidad de persecución penal en a la exposición del sufrimiento que es requerida a las víctimas, en los sentimientos morales que moviliza (Fassin, 1999) e incluso en lo que se entiende por víctimas en cada contexto.

${ }^{9}$ La desaparición de personas es, desde un punto de vista positivista, un eufemismo. Somigliana (2010) sostiene que, en tanto materia, los cuerpos de las personas no desaparecen sino que son ocultados. El ocultamiento de los cuerpos, la desaparición, adquiere, sin embargo, una alta eficacia simbólica en tanto categoría política, alcanzando en el caso argentino un estatus jurídico específico (Da Silva Catela, 2001).
} 
cuya muerte fue constatada y cuyos cuerpos fueron entregados a las familias (Vecchioli, 2013). Aquellos que sobrevivieron tras la prisión, el exilio interno o externo, pero sobre todo aquellos que pasaron por centros de exterminio, quedarían en un estatus liminal, una "zona gris" ${ }^{10}$ que moldearia las identidades que aquí se analizan.

Los sobrevivientes, señala Da Silva Catela (2001), quedaron atrapados en una trama de culpas y reproches, "por haber sembrado la violencia en el país", por haber sido los portavoces de un horror difícilmente audible. EI padecimiento y el ejercicio alternativo de la violencia, asociados al imaginario de la "traición" (Longoni, 2007) y de la "lucha armada", constituyeron desde el principio los dos argumentos más potentes en la posterior deslegitimación de los sobrevivientes en tanto testigos, y de su descalificación como víctimas. A la sentencia del sentido común de "por algo habrá sido" - la cual minimizaba la responsabilidad del Estado culpando a los propios desaparecidos de su desaparición - se sumó una específica a los sobrevivientes de CCDs: "por algo habrá sobrevivido". Esta última, establecería el estigma de la "colaboración" con la represión, obturando la escucha y por ende la palabra sobre estas experiencias, aislándolos de sus anteriores comunidades de pertenencia.

Este estigma pesa más específicamente sobre aquellos que tuvieron un status diferencial dentro de algunos campos donde se aplicó lo que Calveiro (2001) denomina un tipo de tortura "científica" y que reutilizaban a su favor algunos capitales de los secuestrados. En varios campos como la ESMA, Quinta de Funes, La Perla, Olimpo, Vesubio fue generalizada la práctica de mantener con vida a ciertos prisioneros a los cuales se les permitía estar sin venda ${ }^{11}$ y se les adjudicaban tareas. La creación de status específicos para estos secuestrados ("Staff", "mini staff", "viejos", "Consejo", "sin venda", "Quebrados") tiene como corolario la adjudicación del estigma del "colaborador", cuya cercanía de hecho con los represores los vuelve seres "contaminados" (Douglas, 2007), siempre sospechados. Sin embargo, son estas personas las que, por haber permanecido en el campo

\footnotetext{
${ }^{10}$ El concepto de "zona gris" elaborado por Primo Levi (2012) al analizar su experiencia en Auschwitz, y retomado por otros autores como Agamben (2005) y Todorov (1993), alude a una zona de desdibujamiento de los límites entre ciertas categorías estructurales, fundamentalmente entre el bien y el mal como polos morales.

${ }^{11}$ Al llegar a los CCDs todos los prisioneros eran vendados o encapuchados, esto impedía reconocer a sus captores o los lugares donde se encontraban, pero además la dessujeción de los marcos espacio-temporales que implicaba la venda constituía una potente tortura psicológica.
} 
más tiempo, por haber estado sin venda, porque esa familiaridad con la lógica del campo, les permitió ver y saber; se constituyen luego en los principales testigos de lo ocurrido en los mismos.

En lo que a su estatus de víctimas se refiere, el proceso sería más largo y se ajustaría a la genesis de la categoría, que paulatinamente iría incluyendo a diferentes grupos. Aunque la categoría en tanto figura jurídica refiere sencillamente al hecho acotado de haber sido blanco de un delito, la misma nunca es univocal en su aplicación, se ve permeada por elementos extra jurídicos que agravan o atenúan la apreciación sobre el delito según la caracterización que se hace sobre los hechos, el que lo cometió o el que fue blanco del mismo, teniendo en algunos casos consecuencias que permearon decisiones judiciales ${ }^{12}$. Si bien en el caso de los asesinados y desaparecidos la irreversibilidad del daño los torna las víctimas por excelencia, en procesos que implicaron el ejercicio y padecimiento alternativo de la violencia, la disputa a posteriori se cierne sobre quién rompió el estado de pacificación, pudiendo modificar rápidamente la apreciación de la víctima como victimario al actuar "provocando" una violencia mayor. Desprendiéndose de esta situación, existe una apreciación social según la cual habría víctimas "puras" -es decir, incapaces de provocar violencia alguna- a las cuales se les suele agregar el adjetivo de inocentes, lo cual tácitamente configura otro tipo de víctima "impura", la cual es apreciada como total o parcialmente culpable de su propia victimización.

\footnotetext{
${ }^{12}$ Existen casos de total inversión de las responsabilidades, donde las víctimas terminaron siendo acusadas penalmente. Desde el juicio a las juntas, una de las principales estrategias de los represores ha sido intentar descalificar a los testigos como víctimas-como una forma de invalidar sus acusaciones- diciendo que no eran prisioneros sino "colaboradores", es decir parte del aparato represivo. Esta estrategia, reedita una práctica represiva habitual en los CCDs mediante la cual se obligaba a los prisioneros "viejos" a presenciar las torturas de los recién llegados, se los exhibía como "colaboradores" y se calificaba su presencia alli de "participación". Ésta fue una de las técnicas de tortura psicológica más efectivas a la hora de provocar el "quiebre" moral de los prisioneros recién llegados y la vergüenza en los exhibidos, generando la ruptura de posibles lealtades de modo tan duradero que persisten hasta el presente. La estrategia de reeditar esto en la escena judicial resultó en la mayoría de los casos infructuosa desde el punto de vista de la acusación penal -aunque no moral-. Sin embargo, en el último ciclo testimonial un caso trágico fue el de José Baravalle y de Ricardo Chomicki, sobrevivientes de la Jefatura de Policía en Rosario. Baravalle y Chomicki, fueron imputados en la causa Diaz Bessone (2010-2012) acusándoselos de haber "participado en torturas". La imputación, desencadenó el suicidio de Baravalle y el juzgamiento de Chomicki, quien tras haber permanecido preso y transcurrir todo el juicio junto a sus anteriores torturadores, fue finalmente absuelto, ver Chababo et al. (2015).
} 
Quisiera plantear, entonces, que la constitución de figuras jurídicas como las de la víctima necesariamente entraña procesos de identidad más generales (Sarti, 2011) donde se entraman y tensionan regímenes normativos diversos y a veces contradictorios (Zenobi, 2014), como la moral corriente (Pollak y Heinich, 2006), y la Justicia y la moral revolucionaria para este caso específico. Atravesada por estos regímenes, la identidad de la víctima se vuelve maleable, desborda el hecho fáctico que moldea la figura jurídica, precisa ser disputada, inscripta y puesta en escena hasta lograr una representación objetiva -en el sentido de colectiva y legitimada como tal por regímenes de verdad compartidos e instituidos- de los hechos y de las responsabilidades diferenciales del conjunto de los protagonistas en ellos.

Un hecho insoslayable en el establecimiento de las reglas de este juego para el caso argentino es la consagración de lo jurídico como la arena donde se librarían las batallas sobre el pasado reciente. A partir de la reapertura democrática (1983), podemos trazar tres grandes ciclos relacionados ya con una solicitación estatal, y en particular judicial, de la palabra a los sobrevivientes. El primero, comienza con la creación de la Comisión Nacional por la Desaparición de Personas (CoNaDeP) en 1984, el intento posterior de investigación de esos crímenes en el Consejo Superior de las Fuerzas Armadas (ConSuFA) y, fracasado este intento, el desarrollo del Juicio a las Juntas en 1985 . El segundo, con la promulgación de la ley de Punto Final (1986) y el comienzo de un periodo de impunidad donde, sin embargo, la escena judicial no está ausente ya que se desarrollan los Juicios por la Verdad Histórica y otros procesos en el exterior del país, pero durante el cual declinó la pretensión punitiva de esos delitos. Un tercer momento se inaugura con la anulación de las "leyes de impunidad"13 y la consecuente reanudación de los juicios de lesa humanidad desde 2005. En este momento los procesos judiciales se multiplican a lo largo y ancho del país, ampliando significativamente el rango de los delitos juzgados y reavivando la "actualidad" (Agamben, 2005) de los debates aquí abordados.

\footnotetext{
${ }^{13}$ Las "leyes de impunidad" en tanto categorías nativas comprenden la ley de Punto Final (1986) y Obediencia Debida (1987) y los indultos presidenciales (1990). La primera estableció un límite temporal para la presentación de denuncias por desaparición forzada; la segunda eximía de responsabilidad penal a aquellos cuadros del Ejército que hubieran actuado "cumpliendo órdenes"; y mediante los indultos, el entonces presidente Menem "perdona" a los militares anteriormente condenados en el Juicio a las Juntas (1985) y a los miembros de las cúpulas guerrilleras, condenados en 1986. Las leyes de impunidad y los indultos son anulados entre 2003 y 2004.
} 
Durante los dos primeros momentos, la identidad predominante para los sobrevivientes sería la de testigos, resistiendo su clasificación como víctimas una aplicación general a todo el grupo. Un ejemplo significativo de esto es la sentencia de la causa 13/86 - Juicio a las Juntas- la cual dictamina que, si bien puede acreditarse la detención ilegal y sometimiento a tormentos de algunos prisioneros no se encuentra probado que fueron efectivamente obligados a efectuar diversas tareas que les indicaban sus aprehensores sin recibir remuneración alguna. La sentencia -escrito fundacional si los hay en la construcción de identidades relacionadas con la represión - soslaya el hecho para nada menor de la reducción a servidumbre que se estableció a partir de la tortura, llegando a poner en duda su condición de víctimas.

Así, la noción de víctima se aplicaría de forma más general a los sobrevivientes sólo a partir del último de los tres momentos, conllevando en paralelo la elaboración de dispositivos jurídicos y procedimentales que, en conjunto, construirían y performarían tal identidad ${ }^{14}$. En relación a La Perla, este desplazamiento corresponde con el desarrollo de la llamada "Causa Brandalisis"15 (2008), y la mega causa "La Perla" (2012-2016). El listado de las víctimas de la causa Acosta, sin embargo, tiene como base a los denunciantes de la primera hora, quienes entre 1980 y 1985 testimoniaron en el exterior, ante CoNaDeP y en el Juicio a las Juntas ${ }^{16}$. Teniendo en cuenta que los hechos denunciados y los denunciantes son los mismos, cabe preguntarse qué condiciones operaron en el desplazamiento (o en la falta de tal a lo largo de 30 años) que llevó a considerar a los sobrevivientes como víctimas y no ya como meros testigos. Si bien la ley aparece como uno de los instrumentos institucionales más objetivos, el caso de análisis y su devenir histórico deja entrever que, más allá de los hechos juzgados, existe una maleabilidad en la interpretación de estos hechos y de sus protagonistas. Interpretación que se disputa en los

\footnotetext{
${ }^{14}$ Algunos desplazamientos en la jurisprudencia en este sentido fueron clave para considerar el estatus de víctimas de los sobrevivientes, aunque no sin tensiones. En 2005, un fallo del juez Rafecas ampliaba la consideración de la tortura, y con ello de la coacción, otorgando un marco de interpretación novedoso a la supervivencia y a las zonas grises, es decir, a la supuesta colaboración de los sobrevivientes, sobre todo de aquellos que por lo mismo supieron mucho más y terminaron siendo testigos clave.

${ }^{15}$ La misma tuvo como objeto la desaparición forzada de 4 víctimas, miembros del PRTERP, y su posterior asesinato en un enfrentamiento fraguado durante 1977; 8 represores fueron condenados.

${ }^{16}$ En otro artículo desarrollé extensamente estos primeros procesos de denuncia y el lugar de las experiencias personales en los mismos, ver Tello (2015).
} 
resquicios, en las grietas del sistema jurídico y de sus rígidos rituales, y que revela aspectos más estructurales de la vida social.

En las siguientes páginas analizo las disputas en torno a esta figura y la gestión de la identidad de los propios sobrevivientes que es librada en las escenas judiciales. Una de las principales características de estos procesos judiciales contemporáneos es que se trata de juicios orales. Sin precedentes desde el Juicio a las Juntas, los actuales procesos hacen comparecer, y con ello aparecer, muestran, ponen en escena, performatizan las identidades que allí se disputan. Siendo lo judicial uno de los ámbitos más ritualizados de solicitación de la palabra, quisiera analizar a continuación lo que el mismo permite expresar y cómo, en ese marco, las llamadas "introducciones" son planteadas como un género discursivo y performático que escapa al ritual jurídico.

\section{LA AUDIENCIA COMO ESCENA: FLORES, PECHERAS Y PAÑUELOS}

La sala del Tribunal Oral Federal Número 3 de la provincia de Córdoba se encuentra en el edificio de Tribunales Federales. El edificio se alza como una enorme estructura de cemento en una zona que colinda con un descampado, un pequeño barrio y el Parque Sarmiento. La sala de audiencias donde se juzgan desde 2008 delitos de lesa humanidad está en el primer piso. En la antesala de la audiencia se agrupan desde tempranas horas de la mañana aquellos que esperan para ingresar a la misma.

A los lados de la sala un conjunto de tres bancos de un lado y tres del otro se ubican junto a dos puertas también laterales, una que conduce a la sala de los imputados $y$, en frente, otra que lleva a la sala en que los testigos esperan acompañados del Equipo de Acompañamiento Psicológico y del Cuerpo de Protección de Testigos de la Policía. Esa puerta conduce a las áreas restringidas de tribunales y es por donde "aparecen" los jueces, atraviesan el hall y se introducen, pasando por "la puerta de los imputados", en otra área restringida por donde ingresarán a la sala de audiencias. En el medio, entre una y otra puerta, se encuentra el ingreso a la sala de audiencias para el público, precedido de una mampara de vidrio delante de la cual dos policias federales toman los datos a los que quieren ingresar. La gente se distribuye regularmente en el hall: del lado de la puerta de los testigos los concurrentes por la querella, del lado de la puerta de los imputados los concurrentes por los imputados. 
A la sala de audiencias se ingresa por una enorme puerta doble, que da a la parte superior de la sala, que es un anfiteatro completamente recubierto de madera, limitado por dos escaleras laterales. En el medio se ubican 6 filas de 20 butacas que conforman un auditorio que desciende hasta dos metros antes del estrado. De frente a las mismas, sobre una tarima, se alza un escritorio con cuatro imponentes sillones, uno para cada juéz ${ }^{17}$. A sus espaldas cuelga un enorme crucifijo y están apostadas dos banderas argentinas. En el mismo nivel, a la izquierda del estrado, un escritorio más pequeño es ocupado por el secretario del tribunal y tras él se encuentra la puerta de ingreso para los empleados judiciales y los imputados. A ambos lados de los jueces y a la derecha de la entrada principal dos camarógrafos registran. De frente al tribunal se encuentran los escritorios reservados a los abogados querellantes, los defensores privados y las taquigrafas. A su derecha, ubicados lateralmente, los escritorios de los fiscales. A su izquierda, también lateralmente, los de los abogados defensores públicos. Los defensores privados, que son sólo dos, se sientan -en una cercanía casi de cuerpo a cuerpo- entre los abogados querellantes y sus defendidos.

La parte izquierda de las butacas está reservada para los imputados. La misma se encuentra "encapsulada" hasta la altura en que comienzan los escritorios de los abogados dentro de un cubículo de cristales blindados. La "pecera" y la línea que ésta demarca en el sector del auditorio de forma longitudinal separa en el sector del público también a la audiencia: del lado derecho los concurrentes por la querella y el público general ${ }^{18}$, del lado izquierdo y detrás de la "pecera" los de los imputados, en el medio, una fila de policías separa todo el tiempo que dura la audiencia los espacios de uno y otro grupo. La policía se encuentra apostada en varios puntos de la sala, en los ingresos, a los lados, hay uniformados y de civil, van cambiando por turnos según se desarrolla el debate.

Son alrededor de las 10 de la mañana. Entran los imputados ${ }^{19}$, charlan entre sí y con los defensores privados, se ubican en las butacas. Si uno es

\footnotetext{
${ }^{17}$ El tribunal está integrado por su presidente, Jaime Díaz Gavier, además de Julián Falcucci y José Camilo Quiroga Uriburu, el juez subrogante es Carlos Ochoa.

${ }_{18}$ Este público general está usualmente conformado por grupos de estudiantes secundarios y universitarios o por extranjeros.

${ }^{19}$ Los imputados, al inicio del juicio, eran 57. En el transcurso del mismo, y dado que muchos de ellos tienen una edad avanzada, algunos fueron apartados por razones de salud. Tres fallecieron durante el proceso, y uno se suicidó un día antes de que diera comienzo.
} 
capaz de reconocerlos, puede leer en su ubicación su agrupación por Fuerzas represivas y su ordenamiento jerárquico: en las primeras filas se sientan los otrora altos mandos del Ejército, entre los cuales destaca el exGral. Luciano Benjamín Menéndez, hacia atrás los de menor rango pero gran protagonismo como el entonces Tte. Ernesto Barreir ${ }^{20}$, a continuación los civiles adscriptos al Ejército y, más atrás, los policías. Casi todos rondan los 60 años salvo los de mayor jerarquía que son mayores, son todos hombres a excepción de Graciela "Cuca" Antón, ex-miembro del Departamento de Inteligencia de la Policía.

Las jerarquías, y su homología con la clase social de los miembros de este grupo, se expresa también en su vestimenta $y$, en general, en su hexis corporal (Bourdieu, 1986): mientras los rangos más altos del Ejército visten de traje y corbata, zapatos de vestir, están afeitados y peinados dando cuenta de las marcas ciertos consumos de clase y de los requisitos de una pulcritud castrense, los civiles adscriptos y policias exhiben una vestimenta más informal: remeras, zapatillas o alpargatas, y menos cuidados en los detalles cosméticos como el peinado o la barba. Los atributos corporales entre unos y otros son sumamente distintivos: en los de mayor jerarquía el cuerpo erguido, el tono marcial de voz al hablar, el uso de términos castrenses, el modo de sentarse con las piernas cruzadas, marcan la diferencia con sus anteriores subordinados. Aunque no existe barrera física alguna dentro de la pecera, los espacios vacios que dejan entre sí, la interacción y la ubicación de los individuos (adelante los rangos altos) marcan las diferencias jerárquicas entre el grupo a primera vista unificado por su condición de imputados.

A continuación, va entrando el público y distribuyéndose en los dos sectores separados por la línea de policías. Como señala Schoenle, el público "si bien heterogéneo, posee entre sus integrantes supuestos compartidos a partir de los cuales cada uno reacciona, se sienta, habita el espacio jurídico" (2015: 138). Así, el sector reservado para el público de la querella es más numeroso, las personas que integran este grupo portan fotos de los desaparecidos, pañuelos blancos en el cuello o en las cabezas, los cuales se han ido colocando mientras entraban a la sala. Pero el signo

\footnotetext{
${ }^{20}$ Barreiro no sólo fue el jefe de interrogadores de La Perla, sino que también luego ascendió por sus méritos como interrogador a comandar la sección política del Destacamento de Inteligencia 141. Posteriormente adquirió una celebridad pública al iniciar, ante su inminente detención, los levantamientos de semana santa que culminarian en las leyes de Punto Final y Obediencia Debida.
} 
distintivo de este grupo son las flores rojas de papel que llevan en las manos, o tejidas en lana roja y adheridas a sus cuerpos a modo de prendedor, que han sido distribuidas en el hall antes de entrar por miembros de los organismos de Derechos Humanos. Las mismas se han convertido en un símbolo de este juicio en Córdoba, sobre todo desde que en la primera audiencia uno de los imputados, José Arnoldo "Chubi" López, fuera expulsado de la audiencia tras protestar a gritos contra el uso de las flores rojas, según él símbolo del comunismo y "clara provocación". Desde entonces, las flores han sido repartidas en el hall o se prenden en las solapas de los testigos, adornan sus cabellos, son llevadas entre las manos. Si se recibe la flor, se es inmediatamente parte de este sector, ya que, como señala Schoenle (2015), se trata de un espacio "militado" el cual no se puede transitar sin "ser parte".

El sector de los familiares de los imputados, en contraste con el sector de la querella, es mucho menos numeroso. Una, a veces dos mujeres, se sientan allí, destacando una de ellas, la esposa de Barreiro, quien viste una pechera impresa con fotos de "víctimas de la subversión" ${ }^{21}$ y lleva un crisantemo blanco en la mano. Las acciones "militantes" del sector afín a los imputados no tienen como principal destinatario el público, sino los abogados querellantes y principalmente los testigos, que son interceptados e interpelados, o contra los cuales se suelta un comentario en voz alta en pasajes que comprometen a los imputados.

Ambos grupos no interactúan entre si casi nunca. Al interior de los mismos se dan charlas y comentarios hasta el momento en que ingresan los jueces, previamente se han ubicado en sus respectivos lugares todos los que tienen estatus formales en el proceso: abogados defensores y querellantes, fiscales, otros miembros del juzgado. Antes de ingresar los jueces, un

\footnotetext{
${ }^{21}$ Este tipo de acciones se inscriben en una disputa sobre la noción de víctima por parte de las asociaciones de familiares de los represores. Mientras la noción de "víctima del terrorismo de Estado", sostenida por los organismos de DDHH pone énfasis en la excepcionalidad de estos crimenes por haber sido cometidos por agentes estatales en el marco de un plan sistemático, los familiares de los represores, desde la caracterización de los años 70 como una "guerra" entre por lo menos dos bandos, construyen su propia idea de víctima en torno a los "muertos por la guerrilla", a quienes llaman "víctimas de la subversión". Estas asociaciones disputan esta noción de la misma manera que los organismos de $\mathrm{DDHH}$, en los tribunales y fuera de ellos; lo curioso es que sus acciones públicas - que se han incrementado proporcionalmente con el volumen de juiciostoman la simbología construida por los organismos (fotos, marchas, cánticos y gritos de los nombres de los muertos seguidos de un "ipresente!") para poner en escena sus memorias. Para una profundización de la disputa en torno a las "víctimas de la subversión", ver Vecchioli (2013) y Da Silva Catela (2011).
} 
policía dice en voz alta "iDe pie!", todos en la sala se paran al mismo tiempo, los jueces ingresan por la misma puerta que lo han hecho los imputados, en fila. A continuación, el presidente del tribunal indica que todos pueden sentarse y anuncia la entrada del testigo del día.

Hay un breve impasse $y$, escoltado por policías vestidos de civil y por el equipo de acompañamiento psicológico, el testigo entra por la puerta principal, baja las escaleras y se ubica en una silla frente a los jueces, en el centro de la escena, donde los mismos le toman juramento "por sus creencias" de decir la verdad y le advierten sobre las consecuencias penales de mentir, callar u ocultar algo que sabe.

A continuación, le preguntan si conoce a los imputados a lo cual los testigos asienten, algunos se acercan a mirarlos, dicen que los conocen porque estuvieron detenidos en La Perla. Entonces, el presidente del tribunal pregunta si "le competen las generales de la ley", es decir, si tiene con ellos algún vínculo de amistad o enemistad, si es deudor o acreedor de alguno de ellos, a lo que los testigos responden - sistemáticamente-con un conciso "no". El presidente del tribunal enuncia a continuación otra fórmula: "señor/a, usted ha sido citado en calidad de testigo, pero es, sin embargo, víctima de los delitos que aqui se juzgan. ¿Cree que esa circunstancia le impide declarar con la verdad? ¿Lo mueve algún interés personal?" a lo que los testigos contestan, nuevamente, con un conciso "no", al que en ocasiones agregan "sólo que se haga justicia"22. Luego, toman asiento y comienza el testimonio.

Desde diciembre de 2012, asistí regularmente a las audiencias y acompañé a los sobrevivientes, devenidos "víctimas-testigos", en los momentos previos y posteriores a sus declaraciones. A veces dentro de la "sala de los testigos", en la sala de audiencias, en la sala de prensa, he transitado por los lugares públicos y restringidos de Tribunales, por pasillos internos y externos, observando la vida en la Corte y el lugar de los testigos en ella.

En todo este tiempo, la escena antes descrita - aquella que concentra el drama, que pone en escena el pasado- se ha desarrollado regularmente, con variaciones mínimas. El estricto ceremonial de la Corte recuerda al estado teatro balinés de Negara (Geertz, 1999) donde cada uno transita por los espacios diferenciados del palacio, ocupa sus zonas de poder y sus

\footnotetext{
${ }^{22}$ El ritual judicial revela un antagonismo estructural puesto en escena, al tiempo que la suspensión del mismo en pos de una igualación de las partes ante la justicia, como institución pacificadora (Elias, 1997).
} 
zonas impuras, donde la ubicación y la posibilidad de circulación en cada escena forman parte de un drama que todos conocen y que en cierto sentido hace la representación de lo que allí sucede. Las "víctimas-testigos" ocupan, por las horas que dura el testimonio, el centro, el lugar del que debe ser escuchado, nadie puede interrumpirlos ni dirigirse a ellos a no ser por intermedio del Tribunal.

El testimonio es el momento para decir; sin embargo, el ritual jurídico constituye uno de los contextos más estandarizados y menos espontáneos de solicitación de la palabra (Pollak y Heinich, 2006). Mientras la estandarización se cierne tanto sobre lo que puede y debe ser dicho, el control de la espontaneidad se proyecta en la escena de la audiencia en lo que puede o no hacerse y expresarse. La "frialdad" ${ }^{23}$ del contexto judicial y su contraste con la intensidad emocional de las experiencias relatadas exigen al testigo no sólo dominar emociones tales como la congoja en pos de poder hablar, o la ira en pos de no vulnerar la validez de la imparcialidad que exige el testimonio judicial, sino que las emociones, cuando un testigo se "quiebra" 24 , no pueden ser contenidas en un marco de compasión, o no al menos en el momento de la declaración.

El mandato civilizatorio actúa por medio de un doble vínculo (Elias, 2001) sobre las personas: desde afuera ya que cualquier exabrupto puede hacer que la sala sea desalojada, pero sobre todo desde adentro, desde el autocontrol en pos de no vulnerar la continuidad y validez de la declaración. La escena judicial impone, a diferencia de otros regímenes de solicitación de la palabra, un rígido control en la manifestación de las emociones. El sufrimiento, la congoja, la ira que pueden provocar esos recuerdos afloran dentro de cierto equilibrio, ya que los excesos en la expresión del mismo vulnerarian la "objetividad" requerida a un testimonio judicial. Del mismo modo -y dado que los testigos están allí, en cuerpo presente - se establece una necesaria identificación, una comunidad empática con los participantes de la audiencia, donde un defecto en la expresión emocional de vivencias sumamente mortificantes también vulneraría su autenticidad ${ }^{25}$.

\footnotetext{
${ }^{23}$ Este término nativo, lo "frío", designa el contexto donde el proceso civilizatorio inhibe las pasiones, es decir, "lo caliente".

${ }^{24}$ Este término alude a llorar, pero no en cualquier contexto sino en uno donde las normas dictan justamente no expresar emociones, de ahí la connotación de ruptura.

${ }^{25}$ Con esto no quiero decir que el control de las emociones se dé de modo instrumental, ni que sea necesariamente impuesto. El doble vínculo, justamente, regula la expresión 
Otro hecho debe ser subrayado en relación a lo que el testimonio judicial permite. La solicitación judicial de la palabra se enfoca en hechos considerados delitos, pero poco o nada se dice de la identidad individual del propio testigo ${ }^{26}$. El requerimiento de la palabra como víctima - y no ya de mero observador/testigo- motiva entonces la reelaboración de una posición subjetiva frente a los hechos narrados, la cual se plasma en introducciones a algunos testimonios. Este desplazamiento del foco de la exterioridad hacia el relato en primera persona, operó un movimiento similar en la tensión entre la objetivación y la subjetivación inherente al testimonio el cual es, al decir de Calveiro (2006) un relato subjetivo al cual se le exige objetividad y universalidad, un yo que habla, necesariamente, en nombre de un "nosotros" incapaz de atestiguar más que con el hecho de su muerte.

La posición subjetiva del enunciador, plasmada en las introducciones, al igual de lo sucedido con los testimonios en tu etapa original, precisó ser fijada por escrito durante los días, incluso las semanas previas, como si el desplazamiento antes mencionado precisara de una sustancia adherente que permitiera controlar los deslizamientos hacia esa nueva condición de víctimas, vivida en todos los casos de manera incómoda.

Las introducciones, además, dejan entrever un cambio de posición respecto de la institución judicial y las lógicas que la misma propone e impone. Se trata de una irrupción de una palabra que no tuvo solicitación y denota cambios en la posición y los capitales de los testigos respecto de escenas judiciales anteriores ${ }^{27}$.

De las introducciones brindadas por sobrevivientes, las cuales rondan las diez, analizaré dos casos que resultan paradigmáticos y representativos de otras trayectorias testimoniales: las de Ana Iliovich y Gustavo Contepomi. Se trata de dos sobrevivientes integrantes de esos grupos seleccionados

contextual de las emociones ya sea mediante el pudor o el decoro, ya sea mediante la represión externa de los excesos.

${ }^{26}$ A la tensión que el testimonio judicial canónico imprime sobre la subjetividad de los testigos, se suma la pretendida imparcialidad que se requiere de los mismos, donde la pregunta sobre las "generales de la ley", a la vez que tensiona una situación de antagonismo estructural, performa una igualdad frente al arbitrio de la justicia como institución pacificadora (Elias, 1997).

${ }^{27}$ Se verifica esta situación por primera vez en trayectorias testimoniales muy extensas. Tanto en el Juicio a las Juntas como a lo largo de la llamada "Causa Brandalisis" en 2008, los testigos se limitaron a contestar las preguntas que les eran formuladas. 
para "durar" durante el cautiverio ${ }^{28} y$, posteriormente, se convirtieron en testigos clave, declarando muy tempranamente (entre 1980 y 1984). Como he señalado anteriormente, transformarse en los primeros que denunciaran lo que fue La Perla, haber confeccionado las listas de víctimas y represores, pero ante todo sostener que el destino final de los desaparecidos había sido el asesinato expuso a estos sobrevivientes también muy tempranamente- a los juicios de la moral corriente y de sus anteriores comunidades de pertenencia.

Cuando, en 2008, comencé a trabajar con sobrevivientes de este CCD, estas personas eran conocidas como "testimonios". Es decir, si bien sus declaraciones constituían las piedras angulares de todo el saber sobre el campo, sus personas eran sencillamente invisibles. Para acceder a ellos había que pasar por un largo proceso de autorización, dando esto cuenta de una estigmatización que se resolvía en el silencio estratégico o la invisibilidad. Un estigma atribuido y sin muchas posibilidades de réplica, de modo que las introducciones se tornaron, en todos los casos, un instrumento de sutura de esas identidades heridas (Pollak y Heinich, 2006) por la experiencia concentracionaria.

\section{PALABRAS PARA UNA IDENTIDAD HERIDA}

Ana tiene 60 años, estuvo secuestrada en La Perla durante dos. Fue secuestrada en mayo de 1976, de modo que es una de las escasas 10 personas que sobrevivieron a los tres primeros meses de funcionamiento del campo y una de las 2 detenidas en ese periodo que fueron seleccionadas para "durar". Tras su liberación, en un régimen de libertad vigilada, se exilió internamente en Chaco (Argentina) y luego en Perú. Durante el último periodo de su cautiverio, durante el cual fue sacada y llevada nuevamente a La Perla, Ana "robó" información, primero memorizando diez nombres, luego escribiéndolos en papelitos, finalmente copiando las listas que los represores confeccionaban para realizar el inventario de los prisioneros. La información era transcripta en un cuaderno, el cual era celosamente guardado por sus padres en Belle Ville, su pueblo. Antes de partir al exilio, Ana le entregó el cuaderno a CoNaDeP, resguardando su identidad, de modo que la autoría del cuaderno debió ser refrendada en este último juicio.

\footnotetext{
${ }^{28}$ En el caso de La Perla, las personas en esta situación fueron 20 , a lo largo de diferentes periodos.
} 
Ana no quería declarar, el solo hecho de imaginar la mirada de los represores -otra vez- sobre su persona, la sumía en un pánico incontrolable. Cuando en 2008 fue llevada inesperadamente a declarar, Ana cubrió su cuerpo con un poncho. En 2014 accedió a declarar porque la validez de la prueba perdería peso si no lo hacía y en ella había quedado el rastro de gente que nadie había visto, o que nadie había sobrevivido para contar haber visto en La Perla. Exigió, no obstante, algunas condiciones: que sacaran a los represores de la sala, que incorporaran sus anteriores testimonios por lectura -es decir, el relato de los hechos-, y que la dejaran leer un texto que pusiera en contexto su experiencia. En la introducción -escrita durante semanas- Ana explica lo que fue la experiencia que vivió a partir de su secuestro:

Había una mujer barriendo la vereda y un hombre se acercaba caminando. Era sábado. 15 de Mayo con muchas hojas secas. Anduve las calles para encontrar al compañero. Cuando apareció, también dos autos cargados con hombres y armas que pararon y bajaron y nos tomaron.

Yo grité, grité tanto. La señora quiso protestar, defenderme, el señor... los apuntaron y amenazaron. Yo seguía gritando y retorciéndome hasta que una trompada en el estómago quebró mi resistencia.

Me metieron al auto. Al muchacho también. Era sábado, mayo, otoño. Hojas secas, de esas que yo amaba.

Alli en ese lugar, en esa calle de Alta Córdoba, frente a esa señora que quiso ayudarme, empezó la muerte empezó la perla.

El campo de concentración estaba instalado en esa calle de Alta Córdoba: el poder. Esa escena ES el Terrorismo de Estado... es la señora que barre y no puede defender a una chica de 20 años que golpean delante de ella, son hombres apuntándola en una mañana de sábado sin ley, sin amparo (...) Eso fue el Terrorismo de Estado. Y la muerte...la omnipresencia de la muerte. En mi testimonio constante, ese que aparece cuando no lo convido, que se sienta conmigo a decir lo que no voy a decir en el juicio porque aunque lo diga no lo digo, porque nunca alcanza, porque siempre hay más y más y más y más y más. En ese testimonio yo digo (y parece una perogrullada, sin embargo...) yo digo que lo peor fue la muerte. De mi mamá, de mi hijo, de mi compañero, de mi hermano, de mí. (...) y También: la tortura. Que estaba en la venda a los ojos, en la humillación permanente, en la inmovilidad, en las burlas sistemáticas, en la absoluta falta de intimidad, en el hambre, en los gritos de los otros, en el terror, en el Camión. (...) Pero también - $y$, sobre todo- en haber entrado 
en ese territorio de ilegalidad quedando sometidos a la ARBITRARIEDAD ABSOLUTA de los militares secuestradores y sus jefes.

No había reglas, horarios. Todo era inasible, impredecible. EI desayuno podía llegar a las 7 de la mañana, a las 11 o nunca.

La venda podía estar levantada, a media frente o ceñidísima a la cabeza.

Un detenido era torturado hasta morir apenas era secuestrado y a otro lo dejaban tirado en la colchoneta durante dos o tres días sin tocarlo.

Los que te quieren no saben dónde estás...nada de vos... (Testimonio de Ana lliovich, 27 de marzo de 2014)

En esta nueva escena de solicitación de la palabra, donde el sobreviviente es el pivot en torno al cual gira el relato, es necesario, antes que nada, decir "qué fue" y reconstruir el contexto de arbitrariedad, reestablecer las posibilidades de comprensión mutua para poder, desde allí, explicar "qué fue de mí". En el relato de Ana "el campo de concentración" ya no es un lugar aislado, desborda sus límites espaciales, se sitúa en una calle del barrio de Alta Córdoba; al tiempo que es ese territorio inescrutable donde "Los que te quieren no saben dónde estás", la escena "ES el terrorismo de Estado", en presente y con mayúsculas ${ }^{29}$. Ana relata cómo desde una posición de ajenidad, para otros, la sobrevida de esos sujetos des-sujetados de los marcos espacio-temporales habituales, privados de intimidad, pero sobre todo de cualquier capacidad de decisión.

En las introducciones brindadas el tema principal es, además, la muerte. La muerte de los compañeros que compele a testimoniar, pero sobre todo esa no-muerte/no-vida a los que fueron sometidos los sobrevivientes: la muerte social del homo sacer, sin derechos, analizado por Agamben (2005), el hiato moral que generaron las condiciones de ese durar, la exposición, el equívoco:

El verdadero horror es la cercanía con lo perverso. Esa cercanía que contamina con la sola existencia: eso es el verdadero horror... El torturador y el torturado en esa intimidad de "cuerpo presente" que acerca desde la pérdida más absoluta de la privacidad de tu cuerpo desnudo y doliente. ¡NO! no es

\footnotetext{
${ }^{29}$ Es interesante analizar los vaivenes entre la palabra escrita y la oral. Transcribo para este trabajo el propio texto de primera mano, facilitado por Ana, con todas sus marcas originales. Mientras en la lectura su tono es pausado y apenas acentúa algunas palabras, el escrito tiene esa marca de palabras "gritadas", que es la mayúscula.
} 
complicidad, es apropiación. Absoluta asimetría. (Testimonio de Ana lliovich, 27 de marzo de 2014)

Esa cercanía es vergonzante -dice Ana-, "acerca desde la pérdida de intimidad", es una familiaridad impuesta por el asimétrico del poder concentracionario. La vergüenza que la misma desata ante la mirada de los otros, la continuidad moral que la misma rompe, debe ser puesta en contexto, el nivel de responsabilidad también: "no es complicidad, es apropiación". En un contexto de arbitrariedad y asimetría donde, lo hecho no cobra sentido sino en relación a la imposibilidad de elegir pero que, sin embargo, las obliga a explicar(se) constantemente, a limpiar la mancha que dejó esa "intimidad de cuerpo presente", a intentar de revertir la inclasificabilidad en la que el "campo" los sumió y el consiguiente imaginario de la contaminación y el peligro de cara a sus universos sociales previos (Douglas, 2007).

Gustavo fue secuestrado el 1 de julio de 1976 junto con su pareja, Patricia Astelarra, embarazada de 5 meses. Al poco tiempo, su pareja fue trasladada al Campo de la Ribera y luego a la cárcel del Buen Pastor, donde dio a luz. Gustavo permaneció secuestrado un año y medio, también fue seleccionado para "durar", para luego pasar, al igual que en el caso de Ana, por un periodo de "libertad vigilada". Con el retorno a la democracia, él y su entonces pareja confeccionaron un testimonio que fue publicado anónimamente en $\mathrm{La}$ voz del mundo y posteriormente en un libro titulado Sobrevivientes de La Perla (Contepomi, 1983). Poco tiempo después, les fue abierta una causa judicial en base a una acusación infundada, por la cual Gustavo permaneció un año y medio preso y Patricia huyó del país con los tres hijos de la pareja. Gustavo fue sobreseído, pero al Juicio a las Juntas concurrió a declarar estando preso. Luego, se exilió en España. De hecho, Gustavo declaró el 25 de julio de 2013 desde Barcelona, por videoconferencia.

Al igual que en la introducción antes citada, una parte está dedicada a reestablecer la comprensión mutua, a poner el contexto las actitudes propias en la experiencia de ese mundo invertido:

Las diversas formas de sobrevivencia que ocultando el asco nos permitieron evitar la aniquilación para relatar los horrores del sistema represivo merecen un respeto que debería ser sagrado. Recordar y contar lo que nos tocó vivir es una difícil responsabilidad que tenemos derecho a asumir con legítimo orgullo, al fin y al cabo podemos decir que hemos vencido a la represión en el peor de los escenarios. 
Para sobrevivir en La Perla había que simular. Ocultar los verdaderos sentimientos. Y lo que más debía permanecer oculto era el asco, la náusea y repulsión que producian estos acusados, sus personas y todo lo que representaban. Paradójicamente, esa repulsión fue un sentimiento positivo de resistencia, vital, una señal de que no estábamos derrotados.

Sentir asco y ser consciente de ello, nos permitía constatar que estábamos vivos y resistiendo. (...)

A su pesar estoy aqui, y como dije al principio, he sobrevivido para poder denunciar lo que vi en La Perla. (Testimonio de Gustavo Contepomi, 25 de julio de 2013)

Gustavo resalta "asco", hace un gesto de nausea, alarga la ese al pronunciar la palabra para acentuar desde lo gutural la repugnancia. Ningún párrafo puede expresar como este la estrategia de simulación durante la experiencia del campo, donde los sentimientos eran un talón de Aquiles: de ser descifrados por los represores, constituían una poderosa fuente de manipulación. El amor, la preocupación por el otro, las solidaridades debían desaparecer del plano de la expresión, las personas recuerdan haber estado, tras ser seleccionadas para "durar", anestesiadas, indolentes, "como si un muro se alzara ente mis ojos", "como si todo lo que sucediera lo hubiera visto en una película". Había que "ocultar los verdaderos sentimientos", en algunos casos fue el amor que persistía hacia los compañeros, en otro, el asco a los represores, esa es la parte de sí que latió oculta para ser la "base de su reconstrucción". En el testimonio, la explicitación de los mecanismos de supervivencia impuestos por la experiencia concentracionaria, como la simulación, reunifica el plano de la expresión con la perspectiva subjetiva, y con ello la integridad moral desintegrada por la ambivalencia.

Posteriormente esas experiencias aberrantes, la simulación, la involuntariedad del "lancheo" ${ }^{30}$ o de la familiaridad con el sufrimiento, deben ser reintegrada a la propia experiencia, pero sobre todo la

\footnotetext{
${ }^{30}$ En la jerga del campo se llamaba "lancheo" a un procedimiento habitual que consistía en sacar a prisioneros en autos y exhibirlos, hambrientos, harapientos y heridos, en lugares públicos. Este mecanismo tenía como fin que los mismos fueran reconocidos por otras víctimas potenciales, pero tenía además un plus devastador, tanto en el exhibido como en los que presenciaban la escena, la aparición de esos compañeros que consideraban muertos "heroicamente" y que tenian, ahora, la apariencia de zombis. A esto se le sumaba el hecho de que el lenguaje concentracionario llamaba a esto "marcar", poniendo la responsabilidad de la cadena de secuestros en los propios prisioneros y generando enemistades y desconfianzas duraderas.
} 
explicación debe suturar la herida en la identidad infligida por el desdoblamiento impuesto por la lógica concentracionaria ante la mirada de los otros. Porque eso, la exposición en circunstancias indignas, vergonzantes, contrarias a la moral de los grupos de pertenencia es lo que hiere la identidad.

La introducción al testimonio que Gustavo brindó se enfocó en suturar la identidad herida, pero también a hacer una memoria del periodo posterior a su liberación y la consolidación de un estigma, la dificultad para denunciar, las complicidades judiciales que terminaron invirtiendo la acusación, la soledad de este proceso ${ }^{31}$. Al referirse a las acciones penales que se les iniciaron inmediatamente después de denunciar por primera vez, señala:

El objetivo principal fue hacerme callar, y no lo consiguieron. (...) Jamás nadie de la institución judicial nos dio una explicación, ni nos pidió disculpas y mucho menos nos ofreció una reparación.

El objetivo secundario del montaje judicial fue atemorizar y amenazar a otros sobrevivientes y potenciales testigos. En esto sí tuvieron éxito dado que muchos de ellos postergaron indefinidamente sus denuncias mientras otros optaron por permanecer en el exilio.

Debo decir que en todo ese proceso estuvimos solos. (...) Estuvimos solos porque había miedo a las represalias, los represores conservaban su poder y además era la época en que imperaba la teoría de los "dos demonios". Esa teoría, como toda trampa dialéctica, es falsa. Aquí solo hubo un demonio, el de quienes se acostumbraron a gobernar sin necesidad de ganar elecciones, promoviendo golpes de estado cada vez que veían peligrar sus intereses. Violando la constitución que decian defender cada vez que les convino en una historia que convirtió a las fuerzas armadas en el grupo más corrupto de la sociedad y de la historia argentina: terroristas de estado que en su podredumbre llegaron a extremos inimaginables.

(...) Pero también estuvimos solos porque desgraciadamente los sobrevivientes portamos una injusta mancha que los represores hicieron todo lo posible para destacar. No fuimos muchos quienes habiendo tenido la suerte de salir con vida de un campo de concentración decidimos denunciar sus horrores al poco

\footnotetext{
${ }^{31}$ A Gustavo Contempomi se le acusó de haber intervenido en un atentado en los meses previos al golpe de Estado. La orden de detención fue cursada, por el propio Capitán Acosta (uno de los imputados) cuando en 1984, Gustavo los denunció ante CoNaDeP. Luego de permanecer un año preso fue sobreseído.
} 
tiempo de ser liberados. Bastantes menos quienes lo hicimos estando en el país. Con nosotros los represores se ensañaron ferozmente con el objetivo de desprestigiarnos y de paso descargar su responsabilidad, que es intransferible.

(...) Los sobrevivientes somos personajes socialmente muy incómodos porque revivimos las culpas de otros. Por eso era fácil y necesario estigmatizarnos, siempre somos culpables.

Lo fuimos incluso de que nos secuestraran, por haber sido militantes. Lo cual significa que reprimir a los militantes era aceptable. Luego fuimos culpables de sobrevivir, por no haber sido suficientemente heroicos como para morir, lo cual significa que la muerte de los héroes también es aceptable. Demasiado injusto. (Testimonio de Gustavo Contepomi, 25 de julio de 2013)

La palabra de los sobrevivientes debe ser analizada en relación a los estigmas mencionados por Gustavo. Se trata, entonces, de construir una nueva representación de sí que dispute esos estigmas, de revertir esa "injusticia", en palabras de Gustavo. Se intenta achicar la brecha entre su autoridad de hecho para tomar la palabra (vieron, saben, estuvieron allí), la cual los vuelve testigos clave y la autoridad ética vulnerada por el paso por el campo y las posteriores estigmatizaciones.

Si bien desde un primer momento testimoniar por los compañeros caídos se configuró como un deber ético y político, ¿cómo hacerlo sin exponerse a los juicios de la moral corriente? Así, el formato judicial ofreció en épocas anteriores un marco donde poder cumplir con el objetivo principal sin tener que ahondar - más que para fundamentar la autoridad testimonial- en la vivencia en primera persona, incomprendida y ambivalente ante los ojos de los otros. La mayoría de esos testigos clave habian testimoniado ya antes. Pero en casi todos los casos por escrito y de manera solitaria. La tensión entre la autoridad de hecho y la autoridad ética se resolvía así en la invisibilidad o en el silencio estratégico sobre tópicos de dolorosa exposición.

Muchos declararon ante CoNaDeP y en instrucción innumerables veces, pero pocos de ellos habían declarado en audiencias orales, dos de ellos en el Juicio a las Juntas (1985) y un número un poco mayor en 2008 , en el marco de la causa Brandalisis. De modo que, la conjunción entre una trayectoria testimonial extensa (30 años) y el giro que habilita su consideración como víctimas, instó a que algunos de ellos consideraran hacer estas introducciones por escrito. Las mismas desbordan lo judicial tanto en forma como en contenido: por un lado, se pasan por alto los 
estrictos rituales de sucesión de instancias, de la palabra dominada por el interrogatorio, para tomar la palabra -si bien solicitando permisoautónomamente. Se trata, por otro lado, de introducciones extensas, reflexiones, relatos con giros literarios que desbordan los tópicos del interrogatorio judicial pero que apuntan a restituir un contexto a las situaciones vividas, traducir ese mundo invertido y dotar de un sentido a la experiencia. Esa traducción sutura la propia identidad herida por una experiencia que atentó contra la constancia sincrónica y diacrónica, pero sobre todo moral que le hace de andamiaje. Más adelante Gustavo concluye:

Hoy ya no estoy solo. Somos cientos de testigos que coincidimos en nuestros relatos.

Juntos somos la prueba contundente de sus crímenes. Han pasado 37 años desde que fui secuestrado. No les guardo ningún rencor personal a los acusados, solo deseo que se haga justicia. El tiempo siempre pone las cosas en su lugar, a los represores por fin entre rejas. (Testimonio de Gustavo Contepomi, 25 de julio de 2013)

El relato sobre sí pone en contexto lo vivido, reordena responsabilidades. Y con ello, al poder decir, al hacerse escuchar, se comienzan a suturar también las personas morales heridas por las experiencias concentracionarias. Ya no están solos, y el tiempo ha puesto a cada uno "en su lugar".

\section{Aplausos (A MOdO DE CONCLUSIÓN)}

Mientras escribía este artículo terminó el juicio. Fue el 25 de agosto de 2016. Pese a ser invierno, un intenso sol entibiaba el ambiente tanto como la marea conformada por quince o veinte mil personas que se agolparon en la cuadra que antecede a Tribunales Federales. Banderas, cánticos y luego un sepulcral silencio acompañó la lectura de la sentencia leída por el presidente del Tribunal en la sala de audiencias ante un número reducido de gente: aquellos que representaran a ciertos colectivos y autoridades, revelando la trama de legitimidades subyacente al juicio.

Afuera, la lectura fue transmitida y amplificada por parlantes para la multitud. Ante cada condena, la multitud estallaba en aplausos. Gente de todas las edades, munidas de flores rojas, banderas y pancartas, se abrazaba, lloraba, reía, coreaba consignas o insultos. En el escenario, miembros de los organismos de Derechos Humanos, acompañaban la 
lectura con aclaraciones sobre la jerga judicial. Momentos antes, habian leído los nombres de todas y cada una de los desaparecidos que habian sido objeto del juicio. El tribunal dictaminó 28 penas a prisión perpetua, 10 penas que fueron desde los 21 años a los 2 años y 6 meses, y 5 absoluciones. Al terminar las lecturas, el miembro de H.I.J.O.S. (Hijos e Hijas por la Identidad y la Justicia contra el Olvido y el Silencio) anunció: "compañeros: el juicio terminó ¡La lucha continúa!". La multitud estalló en aplausos. Fueron saliendo de dentro de tribunales aquellos actores cuya posición estructural los había posicionado adentro del recinto, entre ellos los sobrevivientes, ahora "víctimas-testigos". La comprobación de los delitos de los que fueron objeto acababan de posicionarlos, univocamente, en ese lugar. ¿Qué pasaría afuera?

Mientras salían por la puerta de tribunales, las personas eran anunciadas. Pasando el umbral se integraban a la marea humana de la manifestación callejera, que iba vivándolos con cada aparición. Madres de plaza de Mayo, Familiares, H.I.J.O.S., abogados querellantes $y$, a continuación, los sobrevivientes. La persona encargada del micrófono comenzó a mencionar, con nombre y apellido, a cada uno de ellos, luego dijo:

\begin{abstract}
Nada de este juicio habría sido posible sin el valiente testimonio de los sobrevivientes, los testigos del horror, los que vieron por última vez con vida a nuestros compañeros desaparecidos y desaparecidas, sin su testimonio nunca hubiéramos podido reconocer a ninguno de los represores. ¡Cuántos años equivocados! ¡Cuánto tiempo nos comimos el verso que tiraron los represores que eran colaboradores! Gracias compañeros, nunca más le vamos a regalar un compañero o una compañera al enemigo. (Notas de campo, 25 de agosto de 2016)
\end{abstract}

Los sobrevivientes, invisibles por fuera de las instancias testimoniales durante cuatro décadas, subieron al escenario en grupo, dijeron unas palabras que fueron replicadas con un inmenso aplauso. El rígido ritual judicial, en su fluir, pareció suturar esas identidades heridas por el drama social que dejó a los sobrevivientes en un estado de liminalidad desprotegidos, solos, sin insignias ni estatus reconocidos- durante casi cuarenta años. Al tiempo que se suturaba su herida, también se suturaba el tejido social desgarrado por la violencia, y algún sentido de la humanidad. El juicio les dio nuevamente un lugar en la estructura, como testigos y como víctimas; en la multitud volvian a ser "compañeros".

Quisiera cerrar este artículo, entonces, con algunas reflexiones en torno a la noción de víctima a la luz de lo analizado etnográficamente. El caso 
muestra, por un lado, las tensiones que objetivamente -es decir, en su reificación - implicó la adjudicación y asunción de la misma para los sobrevivientes y en particular para el grupo de sobrevivientes que conformaron estatus diferenciales dentro de los CCDs y se transformaron, por lo mismo, en testigos clave. Pero el hecho objetivo y obvio de haber sido blanco de un delito, en torno al cual se estructura la figura jurídica de la víctima, se entrama con otros órdenes normativos que tensionan esta representación, para la justicia, para las comunidades de pertenencia de los sobrevivientes, para ellos mismos. ¿Es la figura de la "víctima" un lugar donde se sientan contenidos? Por momentos, el desplazamiento permite, entre otras cosas, dar entidad a la experiencia vivida en carne propia, por momentos la misma parece asociarse a una posición pasiva que opaca la capacidad de agencia (Macon, 2015) o, en las categorías nativas, la condición de "militantes". ¿Cómo conjugar, entonces, estas dos facetas? ¿En qué contextos de solicitación de la palabra?

Como hemos visto a lo largo de este artículo, es sólo a partir del largo plazo que pueden vislumbrarse procesos de sutura en las consecuencias de la implantación de dispositivos concentracionarios en nuestras sociedades. El caso, sin embargo, revela las tensiones entre universos sumamente impersonales, como son el Estado y la justicia, con su expresión más universal, los Derechos Humanos, y contextos específicos, grupos y trayectorias, subjetividades concretas. La figura de la víctima parece, entonces, fértil para pensar los diferentes modos en que la violencia genera identidades en nuestras sociedades; se torna un prisma desde donde mirar las zonas liminales entre lo objetivo y lo subjetivo, entre el sufrimiento y la entidad social que se le adjudica, entre lo individual y lo colectivo.

\section{BiBLIOGRAFÍA}

Agamben, G. (2005). Homo sacer. Valencia: Ed. Pretextos.

Bourdieu, P. (1986). Notas previsionales sobre la percepción social del cuerpo. In VV.AA., Materiales de Sociología Crítica (pp. 183-194). Madrid: Ed. La Piqueta.

Bourdieu, P. (1999). Razones prácticas. Sobre la teoría de la acción. Barcelona: Anagrama.

Burgi-Golub, N. (1998). Émotion, identité, jugement. CURAPP - Questions sensibles, PUF, 59-76. 
Calveiro, P. (2001). Poder y desaparición. Buenos Aires: Colihue.

Calveiro, P. (2006). Testimonio y memoria en el relato histórico. Acta Poética, 27, 65-86.

Contempomi, G., \& P. (1984). Sobrevivientes de La Perla. Buenos Aires: El Cid Editor.

Chababo, R., Nardoni, V., Fernández Lamothe, D., \& Budassoff, E. (2015). El caso Chomichi. Rosario: Ed. Museo de la Memoria.

Da Silva Catela, L. (2001). No habrá flores en la tumba del pasado. La experiencia de reconstrucción del mundo de los familiares de desaparecidos. La Plata: Al Margen.

Da Silva Catela, L. (2011). Memorias en conflicto. De memorias denegadas, subterráneas y dominantes. In D. Lvovich, E. Boholavski, M. Franco \& M. Iglesias (Comps.), Problemas de historia reciente del Cono Sur. Volumen I (pp. 99-124). Buenos Aires: Editorial UNGS - Prometeo Libros.

Douglas, M. (2007). Pureza y peligro. Un análisis sobre los conceptos de contaminación y tabú. Buenos Aires: Nueva Visión.

Elias, N. (1997). Os Alemaes. Rio de Janeiro: Jorge Zahar Editor.

Elias, N. (2001). El proceso de la civilización. México: Fondo de Cultura Económica.

Fassin, D. (1999). La patetización del mundo. Ensayo de antropologia política del sufrimiento. In M. Viveros Vigora \& G. Garay Ariza (Eds.), Cuerpo, diferencias y desigualdades (pp. 31-41). Bogotá: Utópica Ediciones.

Geertz, C. (1999). Negara: el Estado-teatro en el Bali del Siglo XIX. Barcelona: Paidós Ibérica.

Levi, P. (2012). Trilogía de Auschwitz. Barcelona: Océano.

Longoni, A. (2007). Traiciones. La figura del traidor en los relatos de los supervivientes de la represión. Buenos Aires: Editorial Norma.

Macon, C. (2015). Giro afectivo y reparación testimonial: El caso de la violencia sexual en los juicios por crímenes de lesa humanidad. Revista Mora, 21, 63-87.

Malinowski, B. (1973). Los argonautas del pacífico occidental. Barcelona: Ed. Península.

Pollak, M., \& Heinich, N. (2006). “El testimonio”. In L. Da Silva Catela (Ed.), La producción social de identidades ante situaciones limite (pp. 17-32). La Plata: Al Margen. 
Sarti, C. (2011). A vítima como figura contemporánea. Caderno CRH, 24, 5161.

Schoenle, L. (2015). Megajuicios. Extraordinariedad y desborde en el ritual judicial por delitos de lesa humanidad. Clepsidra. Revista interdisciplinaria de estudios sobre memoria, 4, 1134-1150.

Somigliana, M. (2010). Materia oscura. Los avatares de la antropología forense en Argentina. In A. Zarankin (Comp.), Historias desaparecidas: arqueología, memoria y violencia política (pp. 25-34). Córdoba: Encuentro grupo editor.

Tello, M. (2013). Ética y antropología de la violencia. In F. Diaz Duarte \& C. Sarti (Orgd.), Antropologia e ética (pp. 172-229). Brasilia: Ed. Associação Brasileira de Antropología.

Tello, M. (2015). "Yo acuso", un análisis antropológico sobre lo jurídico en los primeros testimonios sobre La Perla. Clepsidra. Revista interdisciplinaria de estudios sobre memoria, 4, 90-114.

Todorov, T. (1993). Frente al límite. México: Siglo XXI Editores.

Turner, V. (1974). Dramas, Fields, and Metaphors. Ithaca: Cornell University Press.

Turner, V. (1979). Frame, flow and reflection. Ritual and drama as public liminarity. Japanese Journal of religious studies, 6(4), 465-499.

Turner, V (1988). El proceso ritual. Madrid: Taurus.

Vecchioli, V. (2013). Las víctimas del Terrorismo de Estado y la gestión del pasado reciente en Argentina. Papeles del CEIC, 2013/1(90), http://www.ehu.eus/ojs/index.php/papelesCEIC/article/viewFile/123 93/11315.

Zenobi, D. (2014). Familia, política y emociones. Las víctimas de Cromañón entre el movimiento y el Estado. Buenos Aires: Antropofagia. 